\title{
Relationship between the Role of the Clinical Instructor, Students' Self-efficacy, and Academic Achievement
}

\author{
Erini E. Tawfeek, Enas Gouda, Shimaa Elaraby ${ }^{\star}$, Wagdy Talaat \\ Department of Medical Education, Faculty of Medicine, Suez Canal University, Ismailia, Egypt
}

\begin{abstract}
Background: Learning environment has a direct effect on students' self-efficacy. In clinical training, instructors should provide the support for their students to cope with this stressful environment and to enhance students' achievement. We examined the role of the clinical instructor and students' self-efficacy by two validated questionnaires to find the relationship between these two factors. Objectives: This study aims to investigate the relationship between the role of the clinical instructor, students' self-efficacy, and academic achievement. Subjects and Methods: This is a correlational and predictive study; the study population included all fifth-year undergraduate (number=154) medical students at the Faculty of Medicine, Suez Canal University (FOM-SCU). The instruments were Medical Achievement Self-Efficacy Scale (MASS) to measure students' self-efficacy and Nursing Clinical Teacher Effectiveness Inventory (NCTEI) to find out the characteristics of the effective teacher from the students' point of view. The academic achievement of the students was measured through their scores in the OSCE exams in six clinical rounds. Results: The descriptive statistics of the two factors of the MASS questionnaire reveals that the students were highly satisfied with factor regarding outcome expectancy with mean=3.59. The descriptive statistics of the six factors of the NCTEI questionnaire reveals that the students were highly satisfied with factor 5 (mentoring) with mean $=4.96$. The Pearson's correlations revealed positive correlation between the construct of self-efficacy and all factors of NCTEI and academic achievement. Multiple linear regression analysis of the mean scores of student's responses to MASS revealed significant predictions. Conclusion: The study concludes that medical students positively perceive their self-efficacy, which influences the development of their interests and goals. So, this study highlights the importance of the role of the clinical educator, especially as a mentor, for enhancing the perceived self-efficacy of the students.
\end{abstract}

Keywords: Self-efficacy, Clinical teaching, Academic Achievement, Regression

\section{Introduction}

Clinical practice experiences give medical students an opportunity to apply concepts learned in class, practice skills learned in lab, and connect with patients, families, and other medical students. Even though students look forward to these experi- ences, they often feel intimated and anxious about them. During clinical practice, stressful situations may emerge, which can increase the students' anxiety level and may hinder the students' learning ability ${ }^{(1)}$. Subsequently, the clinical instructors sought to be empathic, motivational, skillful, available, respectful, and able to in

*Corresponding Author: shimaa8ome@yahoo.com 
crease student confidence. These characteristics help the instructors to be more approachable and the students will probably interact positively with them ${ }^{(2)}$. Furthermore, the instructor needs to realize that giving positive feedback can inspire students to learn more, cooperate with other students, and develop critical thinking. When responding to questions from the students, the instructor needs to have direct and energetic responses ${ }^{(3)}$. Another key characteristic for an effective clinical instructor is the instructors' capacity to teach. The instructors need to guide the students to either the right answer or where to find the answer. Instructors also need to demonstrate new skills to students and could mentor students through the skill and encourage practice ${ }^{(2)}$. Besides, one of the important clinical instructor characteristics is competence. Instructors should be knowledgeable about the area of clinical rotation they are in, being a role model for the students to look up to. Students need to be able to trust the instructor and realize that the instructor is not giving them wrong information. Behavior is frequently learned through observation and modeling. Modeling good skills, techniques and proper behavior by the clinical instructor is part of student learning(3). One of the significant clinical instructor attributes is personality. The instructor should have the capacity to communicate well with students. The instructor should always have a smile, be positive, and always safeguard the student in time of a crisis (4). The instructor should also display a love for teaching and appreciate sharing their experiences with the students. Clinical instructors play an essential role in this experience and can either help or hinder student learning and self-efficacy(2). Bandura (1997) assumed that self-efficacy influences the choices people make, their ways of acting, the effort they spend, their perseverance and elasticity. People are choosing activities for which they feel themselves capable and avoid those for which they do not. Self-efficacy helps individuals to decide how much exertion they will spend on a task, how long they will persist when experiencing challenges, and how flexible they will appear in detrimental situations. The stronger their notion of self-efficacy, the greater their effort, perseverance, and elasticity(5). Self-efficacy refers to 'beliefs in one's capabilities to organize and execute the courses of action required to produce given attainments'(5). Self-efficacy, as a key of component of social cognitive theory, appears to be a significant variable in student learning, because it influences students' motivation and learning(3). According to social cognitive theory, there are four fundamental sources of information that make students' self-efficacy: enactive mastery experiences, vicarious (observational) experiences, social persuasions, and physiological and psychological states ${ }^{(6)}$. Regarding the relation between self-efficacy and achievement, research has been performed at various levels of education (e.g., primary, secondary, university), several areas (reading, writing, mathematics, computing science) and different ability levels (average, talented, below average). These studies (7) reveal the direct and indirect effects of students' self-efficacy on their achievements, relating to several grades and ability levels. The research findings point out that self-efficacy plays a predicting and mediating role in relation to students' achievements, motivation, and learning. During recent decades, the construct self-efficacy has been receiving growing attention in educational research. Several researchers examined the impact of students' self-efficacy on motivation and learning ${ }^{(8)}$. The findings recommend that self-efficacy influences motivation 
and cognition by affecting students' task interest, task persistence, the goals they set, the choices they take and their use of cognitive, meta-cognitive and self-regulatory strategies ${ }^{(9)}$. The Clinical learning environment (CLE) at Faculty of Medicine, Suez Canal University (FOM-SCU) covers both the preclinical years and the clinical years. In the preclinical years (years 1, 2 \&3) the students work in the clinical environment where they have a well-organized structured field training program in Primary heath care centers (PHC centers) and in different community settings. This is besides their clinical training in the Clinical skill labs (CSL). In the clinical years (Years 4, 5 \&6) the students work mainly in the Suez Canal teaching hospital beside field training activities $^{(10)}$. The aim of this study is to investigate the relationship between the role of the clinical instructor, students' self-efficacy, and academic achievement. So, this study was conducted to develop the instructors' behaviors that increase students' learning and to foster the positive elements and alleviate the negative ones for further improvement of the quality of the learning process in clinical setting

\section{Subjects and Methods}

This was a correlational and predictive study, where the clinical instructor's roles and students' self-efficacy were used to predict the academic achievement of the students. The role of the clinical instructor and the students' self-efficacy (in the clinical practice) were considered as predictor variables, whereas the academic achievement was the criterion variable. This study assessed the role of clinical instructor in facilitating the learning process to the undergraduate students and assessing the perceived students' self-efficacy in the clinical practice. Then, the relationship between the role of clinical instructor, student's self-efficacy and the academic achievement of undergraduate students was measured. The academic achievement was tested through obtaining the raw scores of the objective structured clinical examination (OSCE) exams which were held at FOM-SCU, in Ismailia governorate, Egypt, at the end of the round. The study population included the fifth-year undergraduate students at the FOM-SCU.

Sample size: The sample was comprehensive (purposive). All the students in $5^{\text {th }}$ year were included in the sample (154 students) as all the six clinical rounds were included (ENT, Ophthalmology, Dermatology, Orthopedics, Tropical, Psychiatry) to widen our sample size to increase the reliability and validity of the result.

Data collection and Instrumentation 1-Medical Achievement Self-Efficacy Scale (MASS): The questionnaire consisted of seven core themes and 18 items: 1) Medical Expert (3 items), 2) Communicator (2 items), 3) Collaborator (2 items), 4) Manager (2 items), 5) Health Advocate (2 items), 6) Scholar (4 items), 7) Professional (3 items). The MASS questionnaire showed a high internal consistency reliability and good content, discriminant, and predictive validity ${ }^{(11)}$. This questionnaire was used to collect data from the undergraduate students during their clinical training to measure their perceived self-efficacy. This instrument was tested for construct validity and reliability. Exploratory factor analysis (EFA) was performed to identify and interpret the number of factors that could explain most of the common variance. The inventory has five-point Likert response scales ranging from strongly disagree to strongly agree.

2- Nursing Clinical Teacher Effectiveness Inventory (NCTEI): This questionnaire was used to collect data from the students for 
evaluating their perception about the roles of their clinical instructor. NCTEI questionnaire consists of five core themes and 36 items: 1) Teaching ability (17 items), 2) Medical competence ( 9 items), 3) Evaluation (7 items), 4) Interpersonal relations (6 items). 5) Personality ( 7 items). This instrument was tested for construct validity and reliability. EFA was done to identify and interpret the number of factors that can explain most of the common variance. The inventory has seven-point Likert response scales ranging from strongly disagree to strongly agree.

3-The academic achievement of the students: this was measured through their scores in the OSCE exams in the 6 clinical rounds (ENT, Ophthalmology, Dermatology, Orthopedics, Tropical, and Psychiatry).

\section{Ethical Consideration}

The aim of the study and the use of its results were communicated to the participants. Furthermore, no influences were used on the study participants to compel them to participate in the research. The questionnaires were completed anonymously after consenting from the participants to contribute to the research. All data were analyzed confidentially. The research received approval from the Ethics Research Committee at FOM-SCU.

\section{Results}

Out of 154 distributed questionnaires, 151 completed forms were obtained (response rate $=98 \%)$. Most of the respondents were females 94 (62\%), while the male respondents were 57 equivalents to $38 \%$ (Figure 1).

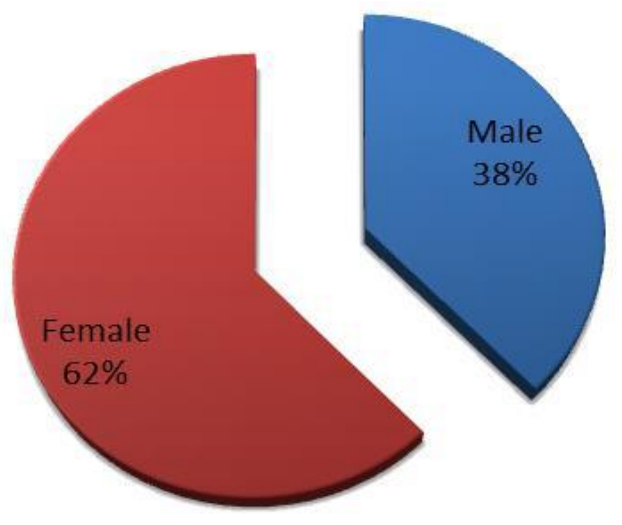

Figure 1: Gender distribution in the study population $(n=151)$

The highest contribution was from the tropical round's students (32) and the lowest one was from the ophthalmology round's students (18) according to their total number in the whole population as shown in (Figure 2). The NCTEI and MASS questionnaires were tested for construct validity and reliability. Exploratory factor analysis (EFA) was performed to identify and interpret the number of factors that could explain most of the common variance. The reliability of the scale was evaluated through tests for internal consistency, using Cronbach's coefficient alpha. We checked the suitability of data for factor analysis by estimating the Sample size of participants which is adequate for factor analysis. The correlation matrix reveals statistically significant, moderate correlations among the observed variables 
used in the analysis. None of the correlation coefficients were large; thus, there was no need to eliminate any variables at this stage.

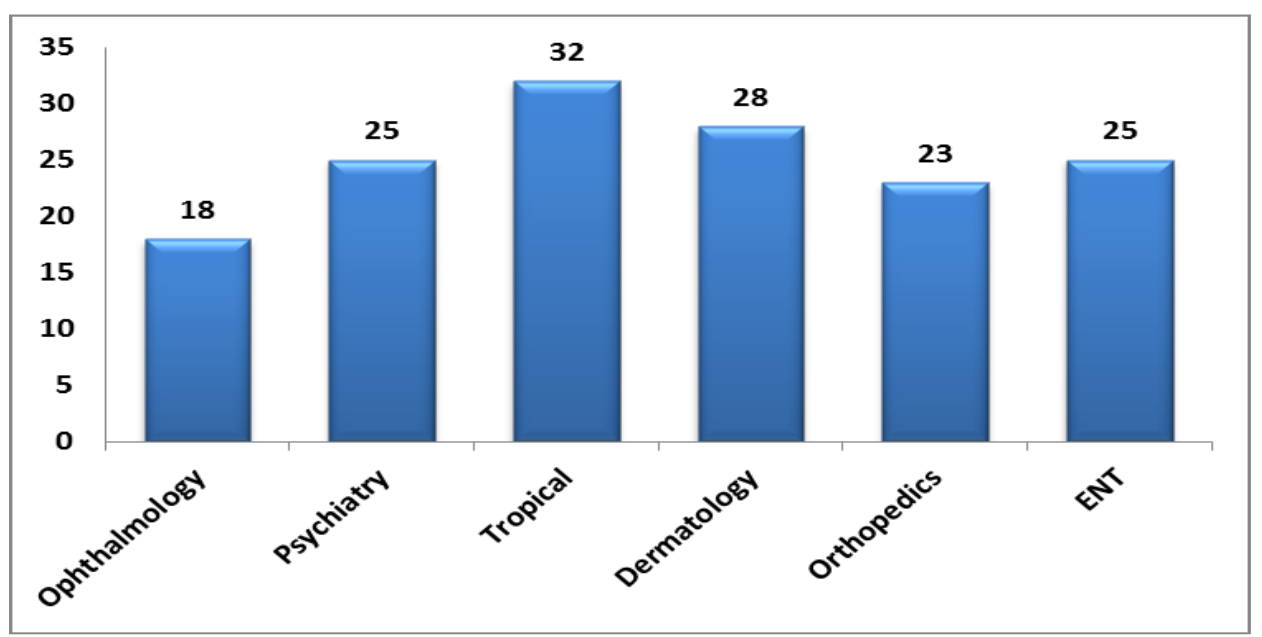

Figure 2: The distribution of the fifth undergraduate students in each clinical round $(n=151)$

Kaiser-Meyer-Olkin Measure of Sampling Adequacy (KMO) and Bartlett's Test of Sphericity.

This test revealed that the KMO Measure of Sampling Adequacy was 0.93 (superb). This value indicates that there were sufficient items predicted by each factor. Furthermore, Bartlett's test of sphericity was statistically significant $(P<0.001)$ which indicates that the variables were significantly correlated. Therefore, this output indicated the appropriateness of the data for factor analysis. Principal component analysis with varimax rotation was performed to identify and interpret the number of factors that could explain most of the common variance and to remove non-reflective or redundant items. The results revealed that the 47 items of the NCTEI questionnaire resulted in seven factors with an eigenvalue >1.00. The 7 factors that emerged from the factor analysis accounted for $74.71 \%$ of the total variance. From the initial 47 items, one item was removed from the analysis. The deleted item was item (13) as it was only one item in the factor. Finally, the questionnaire contained
6 factors and 46 items. Factor 1 included 14 items, factor 2 included 9 items, factor 3 included 10 items, factor 4 included 5 items, factor 5 included 5 items, and finally factor 6 included 3 items. The six factors were labeled as follows: Factor 1: Personality and interpersonal relations. Factor 2: Instructor competence. Factor 3: Evaluation. Factor 4: Teaching ability. Factor 5: Mentoring. Factor 6: Collaboration.

The Cronbach's alpha coefficients of the 6 factors of NCTEI questionnaire: The overall Cronbach's alpha for the total NCTEI items was 0.98. This result indicates high internal consistency (reliability). Regarding MASS questionnaire, the results revealed that the 18 items of the questionnaire resulted in two factors with an eigenvalue $>1.00$. The two factors that emerged from the factor analysis accounted for $65.81 \%$ of the total variance. The questionnaire contained two factors and 18 items Factor 1 included 9 items and factor 2 included 9 items as well. The two factors were labeled as follows: Factor 1: Efficacy expectation. Factor 2: Outcome expectancy. 
The Cronbach's alpha coefficients of the 2 factors of MASS questionnaire. The overall Cronbach's alpha for the total MASS items was 0.96 . This result indicates high internal consistency (reliability). The descriptive statistics of the two factors of the MASS questionnaire reveals that the students were highly satisfied with factor 2 (Outcome expectancy) with mean= 3.59 (Table 1).

\begin{tabular}{|c|c|c|c|}
\hline \multicolumn{4}{|c|}{$\begin{array}{l}\text { Table 1: } \text { Means and SD of the } \\
\text { two factors of MASS Questionnaire }(n=151)\end{array}$} \\
\hline Factors & Number of Items & Means & SD \\
\hline (F1) Efficacy expectation & 9 & 3.56 & 0.87 \\
\hline (F2) Outcome expectancy & 9 & 3.59 & 0.88 \\
\hline \multicolumn{4}{|c|}{ N.B. scales were rated out of 5} \\
\hline
\end{tabular}

While the descriptive statistics of the six factors of the NCTEI questionnaire reveals that the students were highly satisfied with factor 5 (mentoring) with mean $=4.96$ and less satisfied with factor 3 (evaluation) with mean $=4.65$ (Table 2). The Pearson's correlations were tested between the construct of self-efficacy, all factors of NCTEI which measure the role of clinical instructor and academic achievement. It revealed significant and positive correlation to each other (Table 3). Multiple linear regression analysis of the mean scores of student's responses to MASS as predictors of academic achievement revealed that there were significant predictions $(P \leq 0.05)$ between the mean score of the MASS and the academic achievement. This output indicated that the students' self-efficacy could predict academic achievement of the students (Table 4).

\begin{tabular}{|c|c|c|c|}
\hline \multicolumn{4}{|c|}{$\begin{array}{l}\text { Table 2: Means and Standard deviation of the six factors } \\
\text { of NCTEI Questionnaire }(n=151)\end{array}$} \\
\hline Factors & Number of Items & Means & SD \\
\hline (F1) Personality and interpersonal relations & 14 & 4.84 & 1.23 \\
\hline (F2) Instructor competence & 9 & 4.89 & 1.26 \\
\hline (F3) Evaluation & 10 & 4.65 & 1.29 \\
\hline (F4) Teaching ability & 5 & 4.76 & 1.23 \\
\hline (F5) Mentoring & 5 & 4.96 & 1.19 \\
\hline (F6) Collaboration & 3 & 4.89 & 1.30 \\
\hline
\end{tabular}

N.B. scales were rated out of 7; SD= Standard deviation

Also, multiple linear regression analysis of the mean scores of student's responses to NCTEI as predictors of academic achievement revealed that there were significant predictions $(P \geq 0.05)$ between the mean score of the NCTEI and the academic achievement. This output indicated that the role of the clinical instructor could predict the academic achievement of students (Table 5). However, the six factors of NCTEI were used in a stepwise multiple regression analysis to predict the students' self-efficacy. The prediction models indicated that three factors, namely, instructor competence, mentoring and collaboration 
were significant predictors of students' self-efficacy (Table 6). Among the factors of the NCTEI, Mentoring was the most im portant predictor of overall students' selfefficacy and accounted for $48.3 \%$ of the variance (Table 6).

Table 3: Pearson's correlations between the construct of self-efficacy, the role of clinical instructor and academic achievement. ( $n=151)$

\begin{tabular}{|c|c|c|c|c|c|c|c|c|}
\hline & 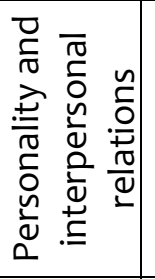 & 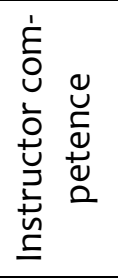 & 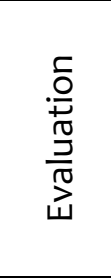 & 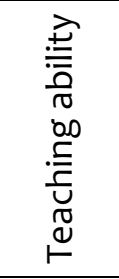 & 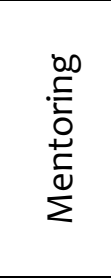 & $\begin{array}{l}\frac{5}{\circ} \\
\stackrel{0}{0} \\
0 \\
0 \\
\frac{0}{0} \\
\overline{\overline{0}}\end{array}$ & 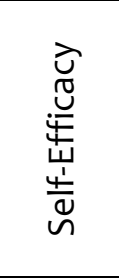 & 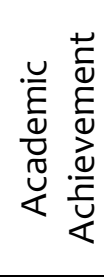 \\
\hline $\begin{array}{l}\text { Personality and } \\
\text { interpersonal } \\
\text { relations }\end{array}$ & & $0.70^{* *}$ & $0.87^{* *}$ & $0.74^{* *}$ & $0.67^{* *}$ & $0.58^{* *}$ & $0.58^{* *}$ & $0.32^{* *}$ \\
\hline $\begin{array}{l}\text { Instructor } \\
\text { competence }\end{array}$ & & & $0.78^{* *}$ & $0.73^{* *}$ & $0.72^{* *}$ & $0.67^{* *}$ & $0.66^{* *}$ & $0.33^{* *}$ \\
\hline Evaluation & & & & $0.80^{* *}$ & $0.73^{* *}$ & $0.65^{* *}$ & $0.66^{* *}$ & $0.36^{* *}$ \\
\hline Teaching ability & & & & & $0.73^{* *}$ & $0.70^{* *}$ & $0.61^{* *}$ & $0.37^{* *}$ \\
\hline Mentoring & & & & & & $0.64^{* *}$ & $0.69^{* *}$ & $0.35^{* *}$ \\
\hline Collaboration & & & & & & & $0.61^{* *}$ & $0.40^{* *}$ \\
\hline Self-Efficacy & & & & & & & & $0.46^{* \star}$ \\
\hline $\begin{array}{l}\text { Academic } \\
\text { Achievement }\end{array}$ & & & & & & & & \\
\hline
\end{tabular}

**. Correlation is significant at the 0.01 level (2-tailed).

Table 4: Multiple linear regression analysis of the mean scores of students responses to MASS as predictors of academic achievement

\begin{tabular}{|c|c|c|c|c|c|c|c|}
\hline \multirow[t]{2}{*}{ Model } & \multicolumn{2}{|c|}{$\begin{array}{c}\text { Unstandardized } \\
\text { Coefficients }\end{array}$} & $\begin{array}{c}\text { Standardized } \\
\text { Coefficients }\end{array}$ & \multirow[t]{2}{*}{$\mathrm{T}$} & \multirow[t]{2}{*}{ Sig } & \multicolumn{2}{|c|}{ ANOVA } \\
\hline & $\mathrm{B}$ & Std. Error & Beta & & & $\mathrm{F}$ & Sig. \\
\hline Constant & 62.93 & 3.59 & & 17.51 & 0.000 & \multirow{3}{*}{21.43} & \multirow{3}{*}{0.00} \\
\hline (F1) Efficacy expectation & 4.99 & 1.67 & 0.38 & 2.98 & 0.003 & & \\
\hline (F2) Outcome expectancy & 1.35 & 1.65 & 0.11 & 0.82 & 0.414 & & \\
\hline
\end{tabular}

a. Dependent Variable: Academic Achievement. b. Predictors: F1 (Efficacy expectation), F2 (Efficacy expectation)

\section{Discussion}

To test these relationships with a high degree of trust, it is important that measuring the constructs of the self-efficacy and the role of clinical instructor is held by instruments with proper psychometric proprieties. So, we tested the psychometric properties of the two instruments for measuring the self-efficacy and role of clinical instructor. The data analysis of testing the construct validity of the MASS questionnaire revealed that the MASS questionnaire is consisted of 18 items, and they were categorized into 2 main factors with 9 items in each factor. The previous findings are comparable to the study of Turan in Turkey who originally developed the MASS questionnaire. He emphasized that MASS Questionnaire items were constructed based on the general competency frameworks of CanMEDs and the Five-star. 
Table 5: Multiple linear regression analysis of the mean scores of students responses to NCTEI as predictors of academic achievement

\begin{tabular}{|c|c|c|c|c|c|c|c|}
\hline \multirow[t]{2}{*}{ Model } & \multicolumn{2}{|c|}{$\begin{array}{c}\text { Unstandardized Co- } \\
\text { efficients }\end{array}$} & \multirow{2}{*}{$\begin{array}{c}\text { Standardized } \\
\text { Coefficients } \\
\text { Beta }\end{array}$} & \multirow[t]{2}{*}{$\mathrm{T}$} & \multirow{2}{*}{ Sig } & \multicolumn{2}{|c|}{ ANOVA } \\
\hline & $B$ & Std. Error & & & & $\mathrm{F}$ & Sig. \\
\hline Constant & 65.15 & 4.06 & & 16.03 & 0.00 & \multirow{7}{*}{5.54} & \multirow{7}{*}{0.00} \\
\hline $\begin{array}{l}\text { (F1) Personality and inter- } \\
\text { personal relations }\end{array}$ & -0.31 & 1.47 & -0.03 & -0.21 & 0.83 & & \\
\hline (F2) Instructor competence & -0.36 & 1.22 & -0.04 & -0.29 & 0.77 & & \\
\hline (F3) Evaluation & 1.22 & 1.68 & 0.14 & 0.73 & 0.47 & & \\
\hline (F4) Teaching ability & 0.73 & 1.32 & 0.08 & 0.54 & 0.58 & & \\
\hline (F5) Mentoring & 0.74 & 1.19 & 0.08 & 0.62 & 0.53 & & \\
\hline (F6) Collaboration & 2.20 & 0.99 & 0.25 & 2.23 & 0.02 & & \\
\hline
\end{tabular}

For each main competency of the CanMEDs at least two items were written, seven experts assured the content validity by aligning the test items to the Ghent general curriculum objectives (end terms), the CanMEDS and the Five-Star Doctor. This resulted in a final version of the MASS, consisting of 18 items to be rated on a fivepoint Likert scale, from strongly disagree to strongly and they categorized the 18 items in 7 categories (medical expertscommunicator-collaborator-manager- health advocate -scholar -professional)(11). The finding of our data demonstrated that the MASS questionnaire covers the most important dimensions of the self-efficacy which is positively reflected on its constructs. These findings indicate evidence for the internal structure validity of the MASS questionnaire. In our study, the Cronbach's alpha coefficient value for the total scale was 0.96. This indicates high internal consistency (reliability) of MASS questionnaire. In addition, internal consistency reliability is, by itself, another evidence of construct validity of the questionnaire ${ }^{(12)}$. This is consistent with the study of Turan who found that the Cronbach's alpha coefficients value was $0.93^{(11)}$. Taken together, the findings in the current study indicate that the MASS questionnaire in clinical practice setting has a high reliability and acceptable evidence of construct validity. The data analysis of testing the construct validity of the NCTEI questionnaire revealed that the NCTEI questionnaire loaded into six factors (components). The previous findings are comparable to the study of Knox who originally developed the NCTEl questionnaire, he emphasized that this questionnaire developed from five categories which are teaching ability, clinical competence, evaluation, interpersonal relationship, personality(13). All the previous factors were also emerged in our study; however, two themes were integrated "personality and interpersonal relationship" and two factors were added in the current study "Mentoring and collaboration" which are very important themes in measuring the quality of clinical teaching. Our study demonstrated that the NCTEI questionnaire covers the most important behaviors of the clinical teacher which is positively reflected on its constructs. These findings indicate evidence for the internal structure validity of the NCTEI questionnaire. In our study, the Cronbach's alpha coefficient value for the total scale was 0.98. This indicates high internal 
consistency (reliability) of NCTEI questionnaire. In addition, internal consistency reliability is, by itself, another evidence of construct validity of the questionnaire ${ }^{(11)}$. This is consistent with the study of Lovrić who found that the Cronbach's alpha coefficients value was $0.97^{(14)}$. The current study findings indicate that NCTEl questionnaire in clinical settings has a high reliability and acceptable evidence of construct validity.

Table 6: Stepwise linear regression analysis of the mean scores of student's responses to NCTEI as predictors of student's self-efficacy as measured by overall MASS scores

\begin{tabular}{|c|c|c|c|c|c|c|c|c|}
\hline & $\begin{array}{l}\text { Uns } \\
\text { izec }\end{array}$ & $\begin{array}{l}\text { dard- } \\
\text { effi- } \\
\text { ts }\end{array}$ & $\begin{array}{l}\text { Standardized } \\
\text { Coefficients }\end{array}$ & $t$ & Sig. & $\mathrm{R}^{2}$ & \multicolumn{2}{|c|}{ AVOVA } \\
\hline & B & $\begin{array}{l}\text { Std. } \\
\text { Error }\end{array}$ & Beta & & & & $\mathrm{F}$ & P- \\
\hline (F5) Mentoring & 0.27 & 0.06 & 0.38 & 4.91 & 0.000 & 0.483 & \multirow{3}{*}{61.50} & \multirow{3}{*}{0.000} \\
\hline $\begin{array}{l}(\mathrm{F} 2) \text { Instructor com- } \\
\text { petence }\end{array}$ & 0.17 & 0.06 & 0.25 & 2.21 & 0.005 & 0.054 & & \\
\hline (F6) Collaboration & 0.13 & 0.05 & 0.20 & 2.10 & 0.011 & 0.019 & & \\
\hline
\end{tabular}

The current study findings revealed that among the six dimensions of the NCTEI questionnaire, the students were satisfied regarding the mentoring role of the clinical instructors. This study revealed that clinical instructor could have an impact on the education of medical students; its implication is that clinical instructor can use these findings as a motivation to be good mentors. The students' perception of the instructors' attitudes can affect how the student thrives in the unfamiliar and oftentimes stressful learning environment of a clinical setting. When students have a positive perception of the instructor, students are more likely to succeed in understanding necessary medical skills. Furthermore, the current study findings also revealed that among the six dimensions of the NCTEI questionnaire, the students were less satisfied regarding the evaluation role of the clinical instructors. Even though feedback is an important step in the acquisition of clinical skills, clinical teachers either skip giving feedback, or the descriptive feedback is not sufficient to enlighten the learners of their strengths and weaknesses.
Skipping of feedback can result in adverse results, some of which can be long-term particularly relating to patient care ${ }^{(11)}$. The previous findings are comparable to a study conducted by Rowbotham, data were collected from a school of nursing at a Midwestern USA comprehensive master's university. The instrument used was (NCTEI) to assess the students' perception of the role of the clinical instructor. His study revealed that among the six dimensions of the NCTEI questionnaire, the students were highly satisfied regarding the evaluation role of the clinical instructor. Rowbotham revealed that providing constructive feedback and being fair in the evaluation process have been considered as the most important skills of the clinical instructor as perceived by the students but in our study the students were less satisfied with the evaluation role. This can be explained by focusing more on content in the clinical setting which does not allow enough time for the students to receive adequate feedback on their progress ${ }^{(3)}$. The current study findings revealed that among the two dimensions of the MASS 
questionnaire, the students were highly satisfied regarding outcome expectation. This means that efficacy and outcome expectations are postulated to influence the development both of interests and goals. Goals are an implicit principle of the career choice and decision process, with plans, decisions, aspirations, and the behavioral choices all including goal mechanisms. Furthermore, strong efficacy and outcome expectations postulate to lead to clearer goals and goal-oriented ${ }^{(15)}$. The previous findings are comparable to a study conducted in public college in the Mid-Atlantic region of the United States as the students expressed their satisfaction with outcome expectation and relate that to their self-efficacy, the study furthermore related the outcome expectation with the expected career satisfaction ${ }^{(16)}$. Our findings are comparable to another study conducted on students at a school of nursing at a Midwestern comprehensive university, the study found also that student perception of self-efficacy is strongly related to how they feel they are meeting their goals and their ability to meet them ${ }^{(3)}$. The Pearson's correlations between the construct of selfefficacy and academic achievement revealed significant and positive correlation to each other. Our findings are similar the study of Chemers on first-year class at the University of California, Santa Cruz he found that academic self-efficacy is strongly related to academic achievement ${ }^{(17)}$. However, our finding was inconsistent with a study conducted at College of Human Medicine, Michigan State University, East Lansing by Mavis on the second-year students he found that the correlation between OSCE performance and self-efficacy ratings was not significant. This study was limited by its sample size which was based on a single cohort of second year medical students( ${ }^{(18)}$. Multiple linear regression analysis of the mean scores of student's responses to MASS as predictors of academic achievement revealed that there were significant predictions $(P \leq$ 0.05) between the mean score of the MASS and the academic achievement. This output indicated that the students' self-efficacy could predict academic achievement of the students. Our findings are like the findings of the study of Turan who originally developed the MASS questionnaire as he applied it in Ghent University on the students enrolled in the medical curriculum in the academic year 2010-2011, results show that the self-efficacy score predicts an acceptable proportion (10\%) of the variance in student performance on the Maastricht Progress Test. In Turan's study they assessed the predictive value of MASS Questionnaire towards a knowledge test while, in our study we tested the self-efficacy's prediction value towards a "shows how" examination (OSCE) as an indicator of academic performance reference ${ }^{(11)}$. The Pearson's correlations between the six factors of role of clinical instructor and academic achievement revealed significant and positive correlation to each other. Our findings are like research which was conducted in Midwestern public university across eight different facilities which found those students with positive relationship with the clinical instructors and who reported them as approachable, mentors, respectful and available for frequent interaction outside the class. The study also found that the perception of effective clinical instructor role had positive correlation and impact on the students' academic achievement ${ }^{(19)}$. Multiple linear regression analysis of the mean scores of student's responses to NCTEI as predictors of academic achievement revealed that there were significant predictions $(P \leq 0.05)$ between the mean score of the NCTEI and the academic achievement. This output indicated that the clinical instructor's behaviors could 
predict academic achievement of the students. Our findings are like the findings of the study of Roop on the third-year students at the Uniformed Services University of the Health Sciences School of Medicine in the United States as they found that teaching behavior, as measured by student assessments was the most significant predictor of student performance. The student achievement scores consisted of the clinical performance evaluation from clinical instructor and three written examinations: National Board of Medical Examiners subject examination in internal medicine; 30-minute multiple choice test in interpretation of laboratory values; and 3hour open book, free response exam of analytic ability, the Multi-Step Examination. Student growth also measured by the difference between the pre-test done before the round and post-test at the end of the round Roop measured both student growth and performance and by relating these to cumulative teaching rating and to specific teaching behaviors he predicted the students' academic achievement, the categories of teaching behaviors used in the study of Roop was similar to our NCTEI Questionnaire (Learning climate, Understanding and retention, Control of session, Communication of goals, feedback, Evaluation) ${ }^{(20)}$. The correlations between the six factors of perceived role of clinical instructor and students' self-efficacy revealed significant and positive correlation between achieving and promoting students perceived effective behaviors of the clinical instructors and enhancing their self -efficacy. Our findings are also similar to the findings of the study of Mueller at The University of Akron who used the same NCTEI Questionnaire, the results of this study showed that there was correlation between the students' perception of instructors' attitudes toward them and self-reported self-efficacy which indicates that student who reports more positive perception of the instructors' attitude towards him or her, also tends to show a higher level of self-efficacy of clinical skill performance. These results suggested those instructors' attitudes toward students who are practicing in the clinical setting could positively or negatively affect the nursing student's clinical self-efficacy. Those findings are consistent with both Albert Bandura's Social Cognitive Theory as well as our research (21). The results of this study showed specifically how perceived clinical instructors' attitudes may influence self efficacy in clinical setting. However, our finding was inconsistent with the study of Rowbotham in school of nursing at a Midwestern comprehensive university as he used the NCTEI questionnaire to assess the role of instructor as perceived by the students, he revealed that teaching ability, nursing competence, interpersonal relationships and teacher personality did not increase the students' self-efficacy and did not reach statistical significance ${ }^{(3)}$. This contradicts our study results where our students were satisfied with their clinical instructor role this could be attributed to the use of different settings, instructional methods and probably to the difference in the clinical educator training as most of our clinical educator are graduates of a PBL school that that adopts innovative strategies in teaching and learning that may cause the difference in the perception of the role of clinical instructor. Six factors of NCTEl were used in a stepwise multiple regression analysis to predict the students' self-efficacy. The prediction models indicated that three factors, namely, instructor competence, mentoring and collaboration were significant predictors of students' self-efficacy. Among the factors of the NCTEI, mentoring was the most important predictor of overall students' self-efficacy. Our findings are similar to the findings of 
the study of Ayden and his colleague. By using of simultaneous regression, they predicted student's sense of efficacy using their relationship with their mentors, the amount of field experiences, and the teaching support. Regression equation accounted for $27 \%$ of the variance in efficacy scores. They found that good mentors are more likely to learn and use new approaches and strategies for teaching, use management techniques that enhance student autonomy provide special assistance to low achieving students, build students' self-perceptions of their academic skills, set attainable goals, and persist in the face of student failure ${ }^{(22)}$. Our findings are also like Komarraju's study as he found that when faculty members interact with students, particularly outside of the classroom; this is related to higher levels of academic self-efficacy for these students. They are more likely to have confidence in their ability to achieve their academic goals due to being respected by faculty that they find approachable, available, and good mentors ${ }^{(19)}$. Our findings are also similar to that of DeFreitas's study as African American and Latino college students were surveyed to examine the influence of involvement with faculty and mentoring on selfefficacy and academic achievement. It was hypothesized that involvement with faculty and mentoring were related to greater academic achievement. It was suggested that the relationship of these factors was mediated by self-efficacy. Involvement with faculty and self-efficacy were significantly related to academic achievement ${ }^{(23)}$. Due to the powerful influence of self-efficacy on academic achievement as we measured in our study, it is important to consider it as a mediator for the influence of mentoring and other forms of studentfaculty involvement on achievement. When students are mentored and have in- teractions with faculty, this is likely to improve their self-efficacy because they are encouraged and provided with a role model. As it was proved, this elevation in self-efficacy is related to improved academic achievement because students now believe that they can do well academically, therefore they perform better ${ }^{(24)}$. Also, the strong relationship between self-efficacy and the role of the clinical instructor, which was revealed from this study, indicates the importance of the clinical instructor as a mentor in improving the academic achievement of the students. The implications of these findings are that the clinical instructors should be trained to play a more influencing role on their students specially regarding their professional development. When, the clinical instructors are good mentors, they increase the self-efficacy of their students helping them to cope with the stressful clinical environment. Thereafter, student achievements will be enhanced by increasing the self-efficacy of the students. Health Professions Education Institutions are recommended to develop professional development programs to increase the clinical instructors' awareness regarding self-efficacy of their students thus promoting a more effective learning environment.

\section{Study Limitations}

The researchers depended only on quantitative research. However, a combination of both quantitative and qualitative data may allow further investigation of areas of problems in clinical teaching and identify their causes.

\section{Conclusion}

The study concluded that students included in this study positively perceived their self-efficacy as the they were satisfied regarding outcome expectation and that 
self-efficacy influenced the development of their interests and goals. Furthermore, the students were less satisfied with the evaluation role of their clinical instructors. Also, there were significant relationships between the students' perceptions of the self-efficacy and their perception of the effective role of their clinical instructors (personality and interpersonal relations, clinical competence, evaluation, teaching ability, mentoring and collaboration), as we found significant correlation between achieving and promoting these effective behaviors in the clinical instructors and influencing the self-efficacy of the students. Moreover, there was a significant relationship between the students' perceptions of the self-efficacy and their perception of the effective role of their clinical instructors and their academic achievement. The study concluded furthermore that both students 'self-efficacy and the behavior of their clinical instructors can predict their academic achievement. Moreover, the behaviors of the clinical instructors can predict the students' self-efficacy. Finally, this study concluded good reliability and construct validity of MASS and NCTEI questionnaires after evaluating the different types of construct validity evidence by EFA and reliability analysis.

\section{References}

1. Melincavage SM. Student nurses' experiences of anxiety in the clinical setting. Nurse Educ. Today. 2011 Nov 1;31(8):785-9.

2. Parsh B. Characteristics of effective simulated clinical experience instructors: Interviews with undergraduate nursing students. J. Nurs. Educ. 2010 Oct 1;49(10):569-72.

3. Rowbotham $M$, \& Owen RM. The effect of clinical nursing instructors on student self-efficacy. Nurse Educ. Pract. 2015 Nov 1;15(6):561-6.
4. Elcigil A, \& Sari HY. Students' opinions about and expectations of effective nursing clinical mentors. J. Nurs. Educ. 2008 Mar 1;47(3):118-23.

5. Bandura, A. Self-efficacy: The exercise of control. New York: W.H. Freeman and Company.1997.

6. Van Dinther M, Dochy F, Segers M. Factors affecting students' self-efficacy in higher education. Educational research review. 2011 Jan 1;6(2):95-108.

7. Carmichael C, Taylor JA. Analysis of student beliefs in a tertiary preparatory mathematics course. Int J Math Educ Sci Technol. 2005 Oct 15;36(7):713-9.

8. Linnenbrink EA, \& Pintrich PR. The role of self-efficacy beliefs in student engagement and learning in the classroom. Read Writ. Q. $2003 \mathrm{Apr}$ 1;19(2):119-37.

9. Hassan AE, Alasmari A, Ahmed EY. Influences of Self-Efficacy as Predictors Of Academic Achievement. Int J Educ Res. 2015; 3:275-84.

10. Talaat W, \& Ladhani Z. Community based education in health professions: global perspectives. Cairo: Regional Office for the Eastern Mediterranean. World Health Organization. 2014.

11. Turan S, Valcke M, De Maeseneer J. et al. A novel Medical Achievement SelfEfficacy Scale (MASS): a valid and reliable tool. Med Teach. $2013 \mathrm{Jul}$ 1;35(7):575-80.

12. Streiner DL. (2003). Starting at the beginning: an introduction to coefficient alpha and internal consistency. J Pers Assess. 80(1), 99-103.

13. Knox JE., \& Mogan J. (1985). Important clinical teacher behaviors as perceived by university nursing faculty, students, and graduates. J Adv Nurs. 10(1), 25-30.

14. Lovrić R, Prlić N, Barać I. et al. (2014). Specificities and Differences in Nursing Students' Perceptions of Nursing Clinical Faculties' Competences. J Prof Nurs. 30(5), 406-417. 
15. Baxter P. The CCARE model of clinical supervision: Bridging the theory-practice gap. Nurse Educ. Pract. 2007.7(2), pp.103-111.

16. Lent RW, Sheu HB, Singley D. et al. Longitudinal relations of self-efficacy to outcome expectations, interests, and major choice goals in engineering students. J Vocat Behav. 2008 Oct 1;73(2):328-35.

17. Chemers MM, Hu LT, Garcia BF. Academic self-efficacy and first year college student performance and adjustment. J Educ Psychol. 2001 Mar;93(1):55.

18. Mavis B. Self-efficacy and OSCE performance among second year medical students. Adv Health Sci Educ. 2001 May 1;6(2):93-102.

19. Komarraju $M$, Musulkin $S$, Bhattacharya G. Role of student-faculty interactions in developing college students' academic self-concept, motivation, and achievement. J Coll Stud Dev. 2010;51(3):332-42.

20. Roop SA, \& Pangaro L. Effect of clinical teaching on student performance during a medicine clerkship1. Am J Med. 2001 Feb 15;110(3):205-9.

21. Mueller SA, Naragon RM, Smith RR. The Relationship Between Nursing Students' Perceptions of Staff Nurses' Attitudes Towards Them and Self-Efficacy in Sophomore-and Senior-Level Nursing Students. 2016.

22. Aydin YC, \& Hoy AW. What predicts student teacher self-efficacy?. Academic Exchange Quarterly. AEQ. 2005. Dec 22;9(4):123-8.

23. DeFreitas SC, \& Bravo Jr A. The Influence of Involvement with Faculty and Mentoring on the Self-Efficacy and Academic Achievement of African American and Latino College Students. Journal of Scholarship of Teaching and Learning. JoSoTL. 2012 Dec;12(4):1-1.

24. Ehrich LC, Hansford B, Tennent L. Educational mentoring: Is it worth the effort? Educ. res. perspect. 2003 Jun;30(1):42. 